\title{
Cerebral Venous Thrombosis and Venous Infarction: Case Report of a Rare Initial Presentation of Smoker's Polycythemia
}

\author{
Mihir Raval ${ }^{a, b} \quad$ Anu Paul ${ }^{a, b}$ \\ aDepartment of Internal Medicine, Sanford Hospital, Fargo, N. Dak., and \\ bUniversity of North Dakota School of Medicine, Grand Forks, N. Dak., USA
}

\section{Key Words}

Polycythemia - Sagittal sinus thrombosis - Secondary polycythemia - Venous infarction

\begin{abstract}
Introduction: Cerebral venous thrombosis is a rare initial presentation of polycythemia. If diagnosed early, treatment can reduce mortality and morbidity significantly. Often it may present with headache as the only complaint, and thus the diagnosis is likely to be missed.
\end{abstract}

Case Presentation: A medically stable 31-year-old male, a chronic smoker with a 17 pack-year history of smoking, was admitted to the emergency room with a 2-week history of gradually worsening, severe, throbbing headache in the occipital region sensitive to light. Initial neurological examination was positive only for some involuntary motor tics of the left leg. Initial laboratory workup showed hemoglobin of $20 \mathrm{~g} / \mathrm{dl}$ and hematocrit of 56.5\%. The carboxyhemoglobin level was normal, but the oxygen dissociation curve was shifted to the left. Further evaluation by MRI and MRA of the brain suggested extensive and complete thrombosis of the superior sagittal sinus, right transverse sinus and right sigmoid sinus with a small venous infarct in the right parafrontal region. Given that the patient first presented with a thrombotic event, workup for primary polycythemia and hypercoagulable disorders was carried out, including JAK2 mutation evaluation, which was negative. This left us with smoking as the only risk factor and possible cause for secondary polycythemia. He improved significantly with phlebotomy and anticoagulation treatment.

Conclusion: This case illustrates a rare but severe complication of secondary polycythemia stressing the importance of being aware of the risk of developing cerebral thrombosis in patients with chronic smoking exposure. 


\section{Introduction}

Polycythemia is a rare condition involving myeloproliferative clonal cells. It is usually diagnosed based on the guidelines published by the Polycythemia Vera Study Group (PVSG), which are subject to constant revision by scientific researchers [1-4].

Polycythemia can present in a variety of ways in patients. Thrombosis is a serious complication of polycythemia and can lead to death in up to $8.3 \%$ of patients [5]. The etiology of thrombotic complications in polycythemia has not been outlined yet, but it is thought that leukocytosis and decreased blood flow due to elevated viscosity is the primary cause of thrombotic events [6-8].

Cerebral sinus thrombosis is considered a life-threatening condition. The incidence of cerebral venous thrombosis (CVT) is around 3-4 per million adults [9]. CVT can be caused by a variety of acquired or congenital diseases [10]. A polycythemia-related prothrombotic state can also present with CVT [10]. Smoking causes combined polycythemia secondary to reduced plasma volume and increased red cell mass due to hypoxia $[11,12]$. Smoking-associated polycythemia can have serious initial presentation in the form of CVT, but there are limited data regarding the actual proportion of patients affected. A review of the literature did not reveal many anecdotal cases or series of case reports of fatal initial presentation in smokers. In the following, a patient with CVT and cerebral venous infarction as initial presentation of polycythemia related to smoking is discussed.

\section{Case Report}

The patient, a 31-year-old male, presented with a 2-week history of gradually worsening headache developing primarily in the occipital region, which was associated with photosensitivity. He described the pain as 10/10, being worse with any kind of movement and exposure to light. One week before, he had been admitted to the emergency room (ER) with similar complaints, and lumbar puncture and a CT scan of the brain were done. All results turned out to be normal and the patient received symptomatic management, but his condition further deteriorated, and he was again admitted to the ER with worsening symptoms.

Except for the ER presentation, his past history and family history were negative for any kind of hematological disease. He was also not taking any medications. He smoked around 1 pack/day for the last 17 years. General examination showed him to be in acute painful distress. His headache exacerbated with walking or head movement. There was no detectable muscle weakness, but there were some involuntary motor tics of the left leg. He reported jerky involuntary on-off movements of the left thigh for a few days. The tip of his spleen was palpable. Ophthalmoscopically, papilledema was not found, and optic disc margins were sharp. The remainder of the systemic examination was unremarkable. His minimental status examination was normal.

Initial laboratory work in the ER showed a hemoglobin level of $20 \mathrm{~g} / \mathrm{dl}$ and a hematocrit of $56.5 \%$. He had leukocytosis $\left(12.4 \times 10^{9} / \mathrm{l}\right)$. Platelet count was $3 \times 10^{5} / \mathrm{dl}$. Cerebrospinal fluid examination revealed levels within the normal range. CSF opening pressure was not reported. In arterial blood gas analysis, carboxyhemoglobin was $2.3 \%$ (normal range $0.0-3.0 \%$ ) and oxygen saturation level (p50) was $23.08 \mathrm{~mm} \mathrm{Hg}$ (normal $25.00-29.00 \mathrm{~mm} \mathrm{Hg}$ ), suggesting a shift of the oxygen dissociation curve to the left. Subsequently, he underwent imaging of the brain (MRI and MRA) that showed extensive thrombosis of the superior sagittal sinus extending to the right transverse and right sigmoid sinus region (fig. 1, fig. 2). There was also a small area of hypointense signaling on $\mathrm{T}_{1}$ and $\mathrm{T}_{2}$ suggestive of venous infarct with hemorrhage in the right parafrontal brain region.

Neurology and hematology-oncology subspecialties were consulted, and the patient underwent workup for hypercoagulable disorders and polycythemia. The workup included lupus, antiphospholipid and cardiolipin antibody levels, JAK2 mutation, factor VIII level, antithrombin gene mutation and 
factor V Leiden level, which were all negative. The erythropoietin level was $11 \mathrm{mIU} / \mathrm{ml}$, which was within the normal range. The homocysteine level was mildly elevated but not to a level that suggested etiology. Comprehensive workup led to the diagnosis of smoking-induced polycythemia causing CVT.

He was managed with therapeutic phlebotomy and body weight control, and heparin was followed by oral anticoagulation with warfarin. The last follow-up showed good recovery, with MRI and MRA suggesting clinical improvement (fig. 3 , fig. 4), with headaches being under control. He stopped smoking, and his last hemoglobin level and hematocrit were $16.9 \mathrm{~g} / \mathrm{dl}$ and $49.7 \%$, respectively.

Informed consent was obtained from the patient prior to the publication of this case report (available on request).

\section{Discussion}

CVT can be caused by a wide range of etiologies, including hypercoagulable disorders, such as factor V Leiden mutation, presence of anticardiolipin antibody, antithrombin gene mutation and polycythemia [11]. Polycythemia is a myeloproliferative disorder that is caused by a variety of etiologies [3] and can be absolute or relative. Absolute polycythemia can be primary (caused mainly by mutation in the JAK2 gene) or secondary [13]. Secondary polycythemia can be caused by elevated serum erythropoietin levels in response to chronic hypoxia leading to excess production of erythrocytes from the bone marrow. Smoking cigarettes creates a unique condition of combined polycythemia secondary to chronic hypoxia, leading to elevated red cell production due to an elevated carboxyhemoglobin level, with concomitant plasma volume reduction $[11,12]$. To date, published studies suggest that polycythemia can present in a variety of ways, but specific initial presentation of smoker's polycythemia, CVT, has not been reported so far [1-3].

CVT is a rare but serious complication of polycythemia [10]. It was suggested that $15 \%$ of patients entering the PVSG trial group had a documented major thrombotic event in the past. The mechanism by which polycythemia causes thrombosis is still under investigation, but, based on previous research, leukocytosis in association with stasis of blood causes hyperviscosity possibly leading to the development of thrombosis [6-8]. Smoking-induced polycythemia is a known condition, but its spectrum of presentation is still underreported due to the rarity of its occurrence. Smoker's polycythemia presenting as CVT is not common, and there is a paucity of anecdotal evidence suggesting such an association. In our study, we aimed to determine the association between smokinginduced polycythemia and CVT after ruling out the most common anticoagulation disorders and primary polycythemia etiologies.

The diagnosis of polycythemia is usually based on the guidelines published by PVSG, which are constantly adapted based on novel research data $[1,2,4,14]$. A group of researchers introduced the use of surrogate markers for the diagnosis of polycythemia, e.g. hemoglobin and hematocrit values instead of the red cell mass value, which is difficult to interpret and not commonly ordered by the clinicians for diagnosis [4]. Smoker's polycythemia is usually diagnosed after exclusion of other causes of primary polycythemia, such as JAK2 mutation and erythropoietin level, and sometimes carboxyhemoglobin, arterial oxygen saturation concomitant with hemoglobin and hematocrit determination $[1,2,12]$. In our case, smoker's polycythemia was diagnosed based on laboratory findings, including a left-shifted oxygen dissociation curve after ruling out primary polycythemia causes. The carboxyhemoglobin level was not elevated, but it is of note that the patient stopped smoking cigarettes after initiation of symptoms, 
i.e. 1 week before hospital admission. Presence of the left shift of the oxygen dissociation curve suggested hypoxia mostly secondary to smoking.

This case report is unique in a way: a young adult with gradually worsening headache and cerebral thrombosis as an initial manifestation of smoker's polycythemia. The importance of addressing this topic is to add to the pool of evidence about smoker's polycythemia. The report emphasizes the importance of being vigilant about the possible occurrence of CVT in smokers with no past history of polycythemia, the primary reason being the high rate of mortality associated with CVT. Various researchers have tried to assess the mortality of patients with untreated CVT, and in the ISCVT study (International Study on Cerebral Vein and Dural Sinus Thrombosis), this mortality amounted to $8.3 \%$ [5]. Evidence also indicates that untreated polycythemia can lead to death within 6-18 months [15]. Specific cause-related mortality of smoker's polycythemia is not reported in the literature so far.

Treatment of smoker's polycythemia is usually directed towards acute treatment of disease and cessation of smoking as long-term benefit. In previous studies, smoking cessation resulted in significantly decreased hematocrit and hemoglobin levels [11, 12]. The patient presented here showed significant improvement following cessation of smoking and anticoagulation treatment, as evidenced by radiological imaging.

There are some limitations to our study. During the evaluation of the patient, protein $\mathrm{C}$ and S, and antithrombin III levels were not checked. Also, workup for systemic inflammatory diseases causing an acquired hypercoagulable state, e.g. Behçet's disease, was not carried out. Although our patient screened negative for occult malignancy, he is still under close follow-up for any signs of malignancy. The possibility of polycythemia vera still exists, as $20 \%$ of cases of polycythemia vera possess a negative JAK2 mutation. In addition, the patient is undergoing further workup for anticoagulation disorders once he is off anticoagulation. At present, despite the limitations of the study, smoking was the most likely etiology for the present findings; therefore, the authors would like to draw the attention to this unprecedented case in light of higher rates of adverse outcomes in undiagnosed cases.

\section{Conclusion}

Cigarette smoking has been associated with many medical problems, and one of those is polycythemia. This case demonstrates an unusual initial presentation of smoker's polycythemia. The present case stresses that cerebral thrombosis should be borne in mind as initial presentation in smokers having headache. Early treatment can significantly reduce morbidity and mortality in patients with close follow-up. These patients should be followed up carefully by hematological and radiological investigation to establish the diagnosis and induce prompt treatment.

\section{Disclosure Statement}

The authors declare that they do not have any conflicts of interest. 


\begin{tabular}{c|l|l|l}
$\begin{array}{c}\text { Case Reports in } \\
\text { NeUlology }\end{array}$ & $\begin{array}{l}\text { Case Rep Neurol 2010;2:150-156 } \\
\text { DOI: 10.1159/000322571 }\end{array}$ & $\begin{array}{l}\text { Published online: } \\
\text { November 22, 2010 }\end{array}$ & $\begin{array}{l}\text { O 2010 S. Karger AG, Basel } \\
\text { ISSN 1662-680X } \\
\text { www.karger.com/crn }\end{array}$ \\
\hline
\end{tabular}

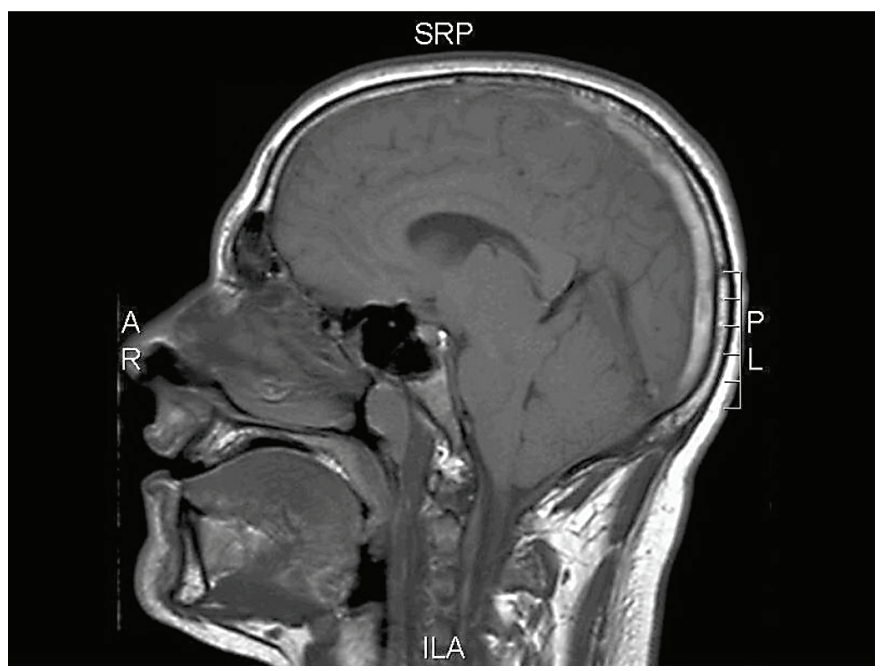

Fig. 1. MRI of the brain: vertical view at the time of presentation suggesting extensive thrombosis of the superior sagittal sinus.

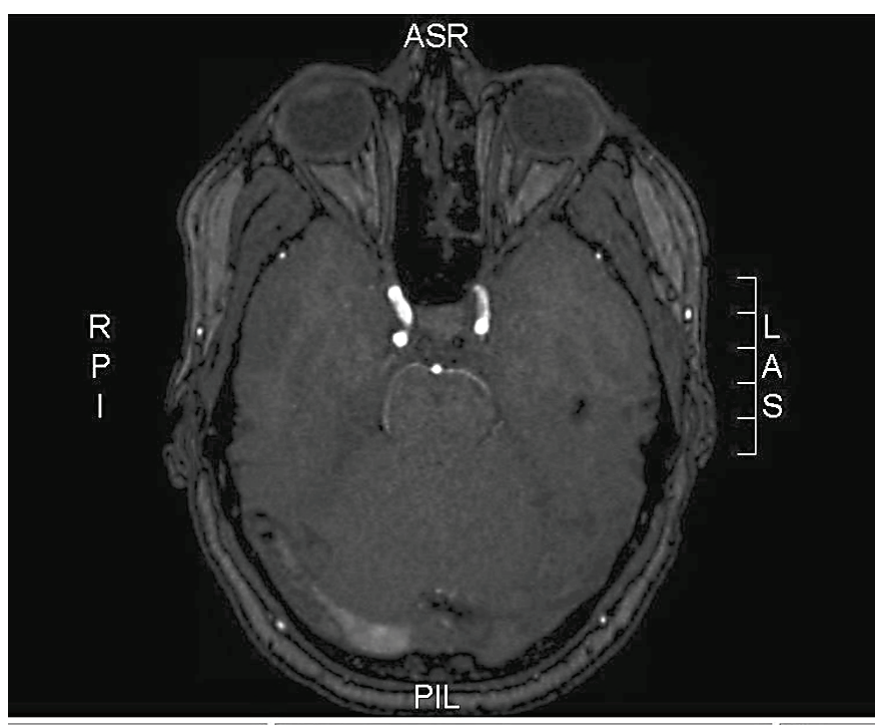

Fig. 2. MRI of the brain: horizontal view at the time of presentation showing thrombosis of the superior sagittal sinus extending into the transverse and sigmoid sinus regions. 


\begin{tabular}{c|l|l|l}
$\begin{array}{c}\text { Case Reports in } \\
\text { NeUlology }\end{array}$ & $\begin{array}{l}\text { Case Rep Neurol 2010;2:150-156 } \\
\text { DOI: 10.1159/000322571 }\end{array}$ & $\begin{array}{l}\text { Published online: } \\
\text { November 22, 2010 }\end{array}$ & $\begin{array}{l}\text { O 2010 S. Karger AG, Basel } \\
\text { ISSN 1662-680X } \\
\text { www.karger.com/crn }\end{array}$ \\
\hline
\end{tabular}

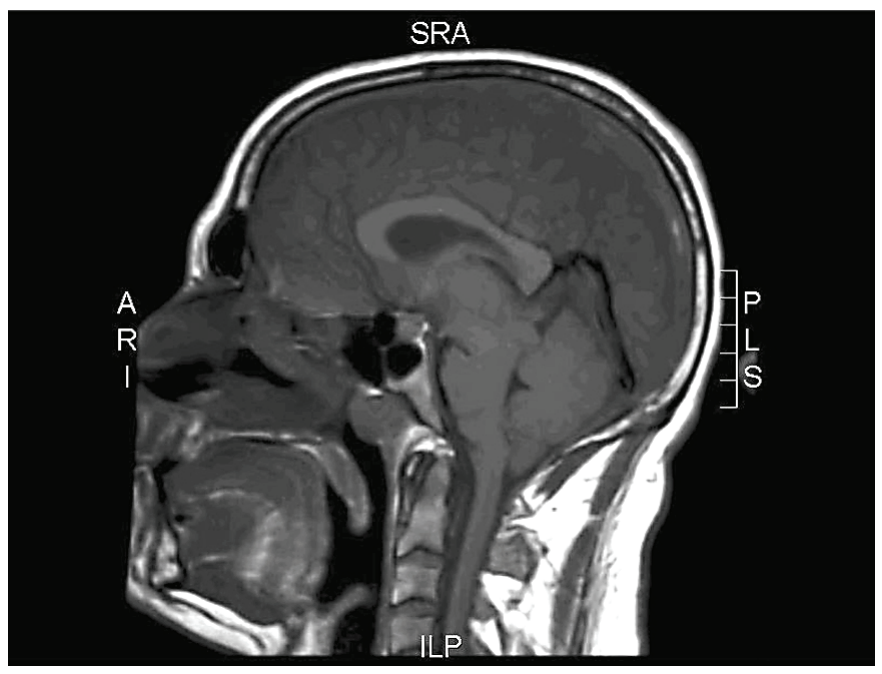

Fig. 3. MRI of the brain: vertical view 3 months after treatment showing improvement with partial resolution of sagittal sinus thrombosis.

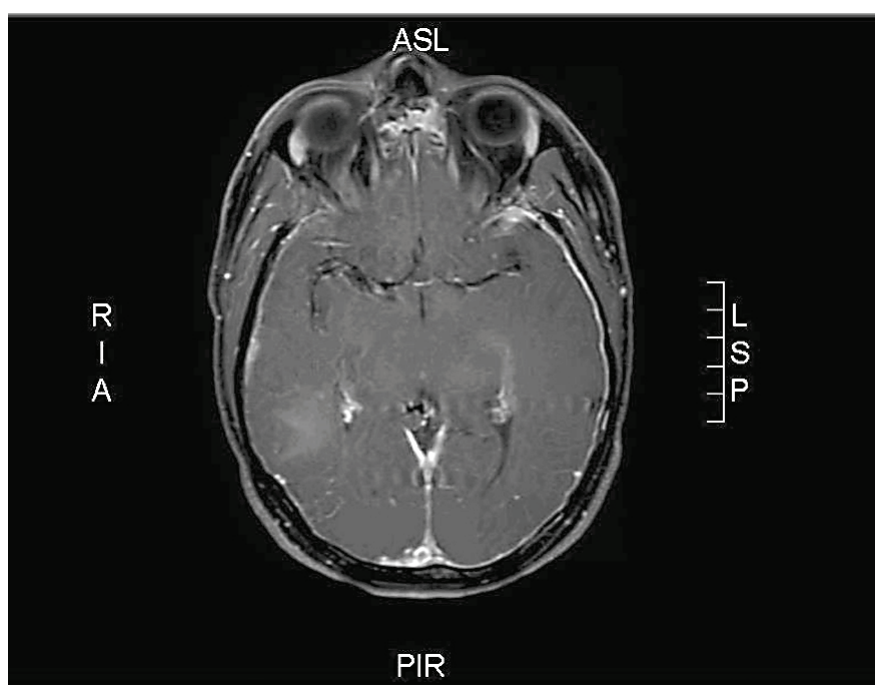

Fig. 4. MRI of the brain: horizontal view 3 months after treatment showing improvement of transverse and sigmoid sinus thrombosis. 


\begin{tabular}{l|l|l|l} 
Case Reports in & $\begin{array}{l}\text { Case Rep Neurol 2010;2:150-156 2010 S. Karger AG, Basel } \\
\text { DOI: 10.1159/000322571 }\end{array}$ & $\begin{array}{l}\text { Published online: } \\
\text { November 22, 2010 }\end{array}$ & $\begin{array}{l}\text { ISSN 1662-680X } \\
\text { www.karger.com/crn }\end{array}$ \\
\hline
\end{tabular}

\section{References}

1 Berlin NI: Diagnosis and classification of polycythemias. Semin Hematol 1975;12:339.

2 Stuart BJ, Viera AJ: Polycythemia vera. Am Fam Physician 2004;69:2139-2144.

3 Prchal JT: Primary and secondary polycythemias (erythrocytosis); in Lichtman MA, Kipps TJ, Seligsohn U, Kaushansky K, Prchal JT (eds): Williams Hematology, ed 8. New York, McGraw-Hill, 2010, chapt 56, pp 823838.

-4 Sirhan S, Fairbanks VF, Tefferi A: Red cell mass and plasma volume measurements in polycythemia: evaluation of performance and practical utility. Cancer 2005;104:213-215.

-5 Ferro JM, Canhao P, Stam J, Bousser MG, Barinagarrementeria F, ISCVT Investigators: Prognosis of cerebral vein and dural sinus thrombosis: results of the international study on cerebral vein and dural sinus thrombosis (ISCVT). Stroke 2004;35:664-670.

6 Landolfi R, Di Gennaro L, Falanga A: Thrombosis in myeloproliferative disorders: pathogenetic facts and speculation. Leukemia 2008;22:2020-2028.

7 Barbui T, Carobbio A, Rambaldi A, Finazzi G: Perspectives on thrombosis in essential thrombocythemia and polycythemia vera: is leukocytosis a causative factor? Blood 2009;114:759-763.

-8 Landolfi R, Di Gennaro L, Barbui T, De Stefano V, Finazzi G, Marfisi R, et al: Leukocytosis as a major thrombotic risk factor in patients with polycythemia vera. Blood 2007;109:2446-2452.

9 Stam J: Thrombosis of the cerebral veins and sinuses. N Engl J Med 2005;352:1791-1798.

10 McBane RD 2nd, Tafur A, Wysokinski WE: Acquired and congenital risk factors associated with cerebral venous sinus thrombosis. Thromb Res 2010;126:81-87.

-11 McAloon EJ, Streiff RR, Kitchens CS: Erythrocytosis associated with carboxyhemoglobinemia in smokers. South Med J 1980;73:137-139.

12 Smith JR, Landaw SA: Smokers' polycythemia. N Engl J Med 1978;298:6-10.

13 Yoo JH, Park TS, Maeng HY, Sun YK, Kim YA, Kie JH, et al: JAK2 V617F/C618R mutation in a patient with polycythemia vera: a case study and review of the literature. Cancer Genet Cytogenet 2009;189:43-47.

14 Michiels JJ, Bernema Z, Van Bockstaele D, De Raeve H, Schroyens W: Current diagnostic criteria for the chronic myeloproliferative disorders (MPD) essential thrombocythemia (ET), polycythemia vera (PV) and chronic idiopathic myelofibrosis (CIMF). Pathol Biol (Paris) 2007;55:92-104.

15 Berk PD, Goldberg JD, Donovan PB, Fruchtman SM, Berlin NI, Wasserman LR: Therapeutic recommendations in polycythemia vera based on polycythemia vera study group protocols. Semin Hematol 1986;23:132-143. 